\title{
EDITORIAL
}

\section{Direction for future scientific research in Sri Lanka}

The socio-economic development of any country is empowered by innovations based on strong foundations of research. This is true for all sectors, particularly science and technology. Taking the above into consideration, the National Science and Technology Commission (NASTEC) along with the Ministry of Science, Technology and Research formulated a National Research and Development Framework (NRDF) to align science and technology research with the national development agenda. In late 2016, a dialogue to develop an implementation strategy for the NRDF was also held.

In mid-2016, the National Science Foundation (NSF) organised a Research Summit to discuss the current status of research and the latest scientific advancements in three selected important areas. This led to the identification of the topics for future research in these priority areas.

The NRDF has identified the issues, research and development needs and interventions needed in ten (10) focus areas. The focus areas included water; food nutrition and agriculture; health; shelter; environment; energy; mineral resources; textiles and apparels; information and communication technology and knowledge sciences; basic sciences, emerging technologies and indigenous knowledge.

The NSF Research Summit held in mid-2016 focused on science technology and innovations issues and gaps in the three areas of food and agriculture, energy and environment, and health. Food, agriculture, energy, environment and health are the common areas of focus identified by both the NRDF of NASTEC and the Research Summit of the NSF. For the country to achieve maximum benefits from these activities, there are several categories of stakeholders who must ensure their responsibilities seriously towards development of future directions in research in these identified areas.

The researchers, academics, industrialists, administrators and policy makers should take into consideration the prioritised recommendations of the NRDF and the Research Summit of the NASTEC and NSF, respectively, when deciding on issues to be addressed in their research programmes. It is imperative for the Ministry of Science, Technology and Research, relevant line ministries and the agencies such as the NSF and the National Research Council (NRC) to allocate funds for research accordingly based on the recommendations.

The researchers while being free to address basic problems, have the responsibility to research on issues faced by the society guided by the recommendations of the NRDF and the Research Summit. They also need to collaborate with the industrialists of the country who are responsible to commercialise the research findings.

If this is not the case, the efforts and funds spent on the deliberations, which led to important recommendations on research requirements of these identified priority areas would have been in vain. Our country can ill-afford such a situation in terms of funds and more so on the efforts of researchers and innovators, which will lead to the development of national policies.

Nalini Ratnasiri 